\title{
In the Making: Constructing In-School Pregnancy in Mozambique
}

Dr Francesca Salvi

School of Education and Childhood Studies (SECS), St George's Building, 141 High Street, Old Portsmouth, PO1 2HY

\begin{abstract}
This article examines current in-school pregnancy policy in Mozambique, Decree $39 / \mathrm{GM} / 2003$, discussing how it discursively constructs in-school pregnancy as a problem, thereby raising the need to regulate its occurrence. Decree 39/GM/2003 indicates that pregnant schoolgirls should be transferred to night courses in order to complete their education. Although progressive in some respects, as it allows pregnant girls to remain in education, the Decree reflects a global tendency to see education and pregnancy as oppositional. As a consequence, the practical implications of transferring pregnant girls to night courses have the perverse effect of encouraging dropout. Stimulated by this contradiction, I reflect on how the policy text produces a deficit view of the pregnant schoolgirl. This Foucauldian process of subjectification results in a strengthening of the opposition between pregnancy and education. As a result, pregnant schoolgirls are 'thrown-out' of their education, defeating the inclusive aims of the national policy.
\end{abstract}

\section{Keywords}

Mozambique, pregnancy, policy, education. 


\section{Introduction}

Concern over access to education in developing countries has been a core theme of the development agenda. At the United Nations (UN) Millennium Summit in 2000, this concern informed Goal 2 (Universal Education) and Goal 3 (Gender Equality), expressing the need to promote universal access to education and to eliminate gender disparities in education by 2015 . Teenage pregnancy is seen as being among the main causes of school dropouts in sub-Saharan Africa (Chankseliani 2008, Eloundou-Enyegue, Stycos, and Jah 2004, Meekers and Ahmed 1999, Grant and Hallman 2006), where it accounts for approximately 18\% of all female dropouts in secondary school (Eloundou-Enyegue, Stycos, and Jah 2004, 3). Data is more pessimistic for Mozambique, where pregnancy accounts for $39 \%$ of the total dropouts in secondary schools and 9\% at the primary level (Eloundou-Enyegue, Stycos, and Jah 2004).

It should not come as a surprise then, that Mozambique has endorsed policy GM/39/2003 (Nguenha 2003) specifically to curb the occurrence of pregnancies within schools. This policy indicates that pregnant girls should be transferred to night courses together with their partners, if in the same school. If these are members of the school staff, they should be made redundant and reported to the police. This policy reflects a global concern over the education/pregnancy nexus, which is summarised by the foreword to the latest United Nations Population Fund (UNFPA) report $(2013$, ii):

When a girl becomes pregnant, her present and future change radically, and rarely for the better. Her education may end, her job prospects evaporate, and her vulnerabilities to poverty, exclusion and dependency multiply.

Teenage pregnancy is here associated with the interruption of education and training, represented as a means to personal development and success, through the acquisition of skills leading to formal employment and individual empowerment. In this sense, schooling is constructed as a symbol of - or entrance to - modernity, while pregnancy and parenthood are defined in terms of the opportunities they prevent. From this perspective, in-school pregnancy works against individual and social progress and is synonymous with backwardness and tradition within a modernising and globalised world.

This doom-laden definition of in-school pregnancy produces a deficit view of the pregnant schoolgirl, and allows little space for elaborating the nuances of young women's situations. For this reason, I use this article to explore how the opposition between education and pregnancy is constructed and reproduced within Mozambican policy discourse. This opens a plane of analysis where policies aimed at bridging the gender gap in education also contribute to reproducing stigma attached to young mothers. They do so by triggering perverse effects, such as preventing pregnant schoolgirls and young mothers from completing their education and training, an outcome opposite to the sentiment of Millennium Development Goals (MDGs) 2 and 3 .

In the next section I discuss the methods I used to put forward my claims and my methodological stance. In Section 3 I position in-school pregnancy in Mozambique within the theoretical and empirical context where the analysis takes place. I then move on to analysing Decre 39/GM/2003 in Section 4. Section 5 and 6 critically examine the current in-school pregnancy policy, discussing how it constructs the problem of in-school pregnancy, and, with it, the need to regulate its occurrence. Last, some conclusions will be drawn in summarising 
the main points raised by this article, and the wider contribution this study makes to effectively working towards including girls in education.

\section{Methodological stance}

This article is part of a wider study whose fieldwork took place within 10 months in and around the capital of Mozambique, Maputo. Data were collected between September 2007 and May 2011. Fieldwork comprised documentary analysis, four focus groups with a total of 20 secondary school teachers, eight focus groups with a total of 40 young men and women (four gender-specific and four mixed-gender) and individual interviews with 10 Ministry of Education officials, 20 secondary school teachers and 33 young people (25 girls and 8 $\mathrm{men} / \mathrm{boys}$ ) in and out of education.

My research strategy in this study has been to break the induction/deduction binary by maintaining a constant openness to construction, deconstruction and interpretation between myself, research participants, and the theorisations I position this study within. I believe, with Laws, that the purpose of analysis is 'to deconstruct the operations of dominant discourses on our everyday lives' $(2011,15)$. This approach has enabled me to depict a world where no single truth exists, but where events are continuously shaped through social processes of meaningmaking.

This article mainly stems out of textual analysis of the policy, combined with excerpts of interviews and focus groups. The official text of the policy was translated in English together with Mozambican educators. My own analysis of it was used in interviews to develop an understanding of how the policy constructed in-school pregnancy. My claim is that pregnant schoolgirls and young mothers in education are discursively produced as in deficit by the current policy text.

Methodologically, I inscribe this claim within postmodern and postcolonial theories. In setting out to discuss how policy formulation constructs the subjects it aims to regulate, I rely on Foucaldian notions of discourses. These move away from the concept of truth as singular and objective, to introduce a knowledge that is plural and subjective; truth becomes then a 'regime of truth' (Foucault and Gordon 1980,112) which temporarily sits over wider webs of meaning. These webs of meaning are what Foucault referred to as discourses, and are responsible for making both the self and the world intelligible. As Hall $(1996,10)$ puts it:

The subject is produced 'as an effect' through and within discourse, within specific discursive formations, and has no existence, and certainly no transcendental continuity or identity from one subject position to another.

It is through language, and practices of meaning that subjects are made into what they are, and yet they do not exist beyond those very same structures. Foucault (1977) identifies these workings of power as 'disciplines' or 'technologies' aimed at regulating selves in docile bodies. It is this docility, this inscription of individuals within preordained webs that becomes necessary for forming individual identity. This theoretical position allows me to explore how decree 39/GM/2003 attempts at normalising the female subject.

This perspective is very powerful. It means, for instance, that certain descriptions of teenage pregnancy not only describe it, but constitute it. In other words, looking at how in-school pregnancy is described by the policy text becomes an act of dissection. Through it, I aim to 
shed some light over the discourses used to render in-school pregnancy intelligible. At the same time, this act suggests that there may be other aspects of in-school pregnancy that remain outside of those webs of meanings. This perspective resonates with Youdell $(2006,2)$, who offers a nuanced perspective over the subject and claims:

Persons are not 'who' they are because of some natural or essential nature, some inner state. [...] persons come to 'be' 'who' they are by being intelligible within discourse, the bodies of meaning that frame social contexts. Impossible bodies and impossible selves, then, are outside those frameworks of meaning. They are unintelligible, they are not persons.

Youdell identifies the ruptures between the modern subject, a product of their biological nature, and the post-modern subject, created by their history, and rendered intelligible through the notion of discourses. Similarly, exposing processes implicated in the workings of discursive power entails looking at the micro-politics of power, the everyday practices and norms that regulate behaviour and produce and reproduce discourses. Here, the process of subjectification is not only discursive, but it is also hierarchical as some discourses interconnect in setting the norm, hence defining what is or should be the standard of normalcy.

\section{Positioning In-School Pregnancy}

Ministerial Decree 39/GM/2003 figures as the national response to the global concern over pregnancy as an obstacle to self-realisation through education and employment. In this respect, it resonates with similar policies developed in other Southern African countries. For instance, extensive research has been carried out in South Africa in order to discuss the conflicting relationship between pregnancy and parenthood on one hand, and schooling on the other (Bhana et al. 2008, Morrell, Bhana, and Shefer 2012, Shefer, Bhana, and Morrell 2013, Bhana et al. 2010). Although the drive towards equality has heavily impacted on the educational agenda, the experience of being pregnant or parenting while at school remains influenced by broader discourses on adolescence, pregnancy, parenting, gender and female sexuality in general (Shefer, Bhana, and Morrell 2013). These tend to reproduce a negative representation of teenage pregnancy, and teenage mothers as deviant, thereby contributing to excluding young mothers from educational spaces, despite inclusionary policies.

Shefer et al (ibid.) explain this by describing in-school pregnancy as a threat to traditional notions of authority and order. This - they claim further - is to be linked to the dominant childhood-adulthood binary, in which the pregnant school girl is depicted as transgressing boundaries. Educational institutions and pregnancy policies, on the other hand, work to normalise these behaviours, and do so by developing sets of norms aimed at reproducing an institutional regime and at positioning individual identities accordingly.

The construction of pregnancy in opposition to education has contributed to othering and devaluing parenthood. For instance, Thomas $(2007,48)$ laments how childbearing has remained largely unexplored within African social and symbolic life. Among those who have engaged with such themes, Mikell identifies the central role played by fertility and motherhood in defining women's identities in postcolonial Africa by suggesting pronatalism as a key tenet of 'emerging African feminism' (1997, 4). Similarly, Amadiume (1997) suggests the centrality 
of motherhood may not have been taken seriously by a Western tendency to 'patriarchalise' (Arnfred 2004, 207) local structures. More specifically, Western eyes have traditionally conflated the status of motherhood with that of wifehood, seeing subordination and dependency as feature of the latter status. This way, motherhood has failed to be acknowledged as a 'locus of power and autonomy' (ibid.).

Childbearing and motherhood, instead, have been the 'main source of a woman's respect' since the precolonial period (Iliffe 2005, 264), invoking a regulatory framework which puts pressure on girls to have children early (Loforte 2007, 29). Parenthood seems thus to reinforce particular gender regimes, a term first coined by Kessler et al. (1985) and articulated by Dunne (2007, 502) as:

\section{[...] constructed through institutional practices (with inscribed social relations of gender), which symbolically construct and regulate everyday life and normalise unequal power relations.}

The concept of gender regime builds on a discursive understanding of the subject and explores the gendered norms at work in particular contexts, including the extent to which these make assumptions about heteronormativity. In relation to the reproductive capacity of both men and women, fertility is identified as an important signifier of gender. A teenage pregnancy may thus be encouraged in high fertility societies in order for girls to prove their reproductive capacity and qualify as potentially good wives in view of a marriage (Price and Hawkins 2001, 200). For men in such societies, fatherhood is highly valued as it provides a sense of belonging in patriarchal societies and determines which ancestors will protect the baby (Jewkes, Morrell, and Christofides 2009, 681).

This perspective moves beyond the conceptualisation of teenage pregnancy as an obstacle to self-realisation. It permits to consider how pregnancy and parenthood may also contribute to self-realisation. Children are so important that pregnancy and parenthood are considered as rites of passage to womanhood (Preston-Whyte and Zondi 1992), where parents gain a different social status. Osório \& Cruz e Silva $(2008,291)$ claim that in Mozambique pregnancy is conceived as a rite of passage regardless of the mother's age. Pregnancy determines an individual's position within the extended group, as it modifies teenage mothers' social status by distancing them from their peers while strengthening familial bonds instead. A similar position is embraced by Mkhwanazi (2010), who looks at the management of teenage pregnancy as a form of transition rite in South Africa. This is to be understood in a context characterised by the weakening of formal female initiation rites, which gives pregnancy a high degree of symbolic power. In this context, Mkhwanazi claims that 'a girl's transition to motherhood presented an opportunity for both mother and daughter to demonstrate their adherence to local ideals' (356) by fitting in with a gender regime that revolves around motherhood and respect towards the code of seniority.

Jewkes et al. $(2001,734)$ argue further that teenage fertility is infinitely preferable to the possibility of infertility in South Africa, as having children figures as a distinctive trait of womanhood. A similar point has been made in relation to Mozambique, where childless individuals are perceived to be incomplete (Andrade et al. 2001, 32). Similarly, Runganga et al. (2001) discern the values and positive meanings attached to fertility by looking at reproductive failure in Zimbabwe. 
With this discussion I wish to suggest that a disconnect may exist then between a discourse of motherhood which is valued and which positively contributes to identities, and a discourse of "degeneration"(Macleod 2011) that permeates in-school motherhood. Studies coming from a development background tend to rely on a modernist conception of the individual. This entails a schism between the body and the mind, whereby the body is the site of 'irrationality, passion and moral corruption [while] the mind functions as the seat of reason and restraint' (BakareYusuf 2004, 1). In this sense, young people are supposed to (want to) invest in their education and training, which will facilitate access into employment, before they have children. Yet, job markets may offer limited options in developing countries, leaving individuals with no tools for realising their aims and ultimately preventing sufficient appreciation of their agency.

\section{Decree 39/GM/2003}

As anticipated in the introduction, Decree 39/GM/2003 postulates the transferral of pregnant schoolgirls from day to night courses. In advance of exploring the construction of in-school pregnancy through the textual analysis of decree $39 / \mathrm{GM} / 2003$, I will situate the policy in its historical and international context, and discuss its practical implications.

\section{$\underline{4.1 \text { Policy in Perspective }}$}

Chilisa (2002) reviews sub-Saharan in-school pregnancy policies and distinguishes three kinds of policy: expulsion, re-entry and continuation, where the latter are the most progressive. Although Chilisa (ibid.) categorises Mozambique (at the time of her review) as adhering to rigid expulsion policies, the country has since adopted a continuation policy, enabling pregnant girls to remain in education, provided they transfer to night courses. Decree 39/GM/2003 marks thus a shift and reflects Mozambique's process of (wider social) transition. Moreover, it is the first national policy to advise on how to manage in-school pregnancies in Mozambique and has served the aim of unifying the country accordingly. Mr Paulo, an official within the Ministry of Education, reported:

During the single-party regime there was no pregnant girl in schools. Before decree 39/GM/2003 each school had its own internal regulation. They had codes of conduct, but I can tell you that no pregnant girl would be admitted to any courses of any school in the country. This decree established some progress. In itself, it is the first public policy developed at national level to regulate in-school pregnancy and its first goal is to allow for more girls to remain in education and graduate.

In this light, transferral marks a development of previous norms. For Mr Paulo, who has worked in education all of his life, the shift is extremely progressive: transferral is a means to allow pregnant girls and young mothers to remain in education, thereby working to bridge the educational gender gap. This can be read as a form of 'inclusion through exclusion' (Foucault 1994, 78), as pregnant schoolgirls are allowed to remain in education, provided they are transferred to an alternative setting.

Before 2003, institutions and individuals would rely on customary laws and traditions to deal with cases of in-school pregnancy. These, in turn, would build on traditional gender models situating parenthood within the household. Women who gave birth were thus expected to leave the classroom, and embrace a more housebound gender regime. Decree 39/GM/2003 allows 
instead for a more nuanced approach to womanhood, where pregnancy and schooling are not mutually exclusive in the definition of individual identity.

Decree 39/GM/2003 seems to provide a useful response to addressing in-school pregnancy. On the one hand it marks some improvement from the previous custom of expelling pregnant girls by allowing them to remain in education and complete their degree. On the other hand, the decree sends a clear message: pregnancy is not welcome within educational institutions. Strategically, transferring girls to night courses also becomes a deterrent for other girls, by symbolising that a pregnancy will not be condoned. Ultimately, Decree 39/GM/2003 is an attempt to de-normalise in-school pregnancy, by reducing its visibility or limiting it to specific sections of the day, namely, those traditionally allocated to adult education. Overall, it seems to provide a functional operationalisation of MDG 2 and 3 in its aims and implications.

Yet, the practical implications of Decree 39/GM/2003 render it problematic on a number of levels. Although formally working as a re-entry policy, transfer to night courses may act as a highway to dropout, as I argue in the next section.

\subsection{Transfer or Dropout?}

Transferring pregnant girls to night courses entails at least five problematic factors, which are key for understanding the tight interconnections between transfer and dropout. The first has to do with public transport, as Zelia, out of school in connection to a pregnancy, explains:

I had to leave the house one hour before the beginning of classes, keeping into account that I was going to get stuck in traffic somewhere. Also, I had to change buses on the way, which means that I had to wait and often do so by myself. That is not nice at night.

Night courses start at $6 \mathrm{pm}$ and last until $10 \mathrm{pm}$. That means that pupils attending classes need to account for rush-hour traffic on the way to school and to deal with the scarcity of transport on the way back. Journeys back and forth between home and night school are likely to be more time consuming than during the day, increasing the opportunity cost of remaining in education.

A second reason concerns the increased danger of being out and about at night, as Ersilia, 16, points out:

I really do not like it, to go to school at night I mean. I live in Hulene, it takes me an hour to get there if traffic is light. The problem is, the traffic is never light. [..] Plus it gets dangerous at night. To be honest, I am not sure whether I am going to resist or not. I think it becomes very easy to drop out when you are going to school at night.

Having to cover long distances at night leaves girls more exposed to the potential risk of being assaulted. Clearly nobody wants to be exposed, but pregnant girls may feel even more vulnerable.

A third factor is to be found in the quality of night courses, as Zelia points out:

The problem for me was the quality of teaching at night. There are not many subjects and teachers do not explain things properly. People make a lot of noise, and in the end, you are lucky if you learn one thing out of ten. It is a parking lot more than a school. Teachers have taught elsewhere all day, and they are tired. 
They also think that if you go at night it means school is not that important to you, that you have another priorities during the day.

Teachers' voices are quite insightful in depicting a system that does not allow night courses to be effective. Teachers are often forced to double or triple shifts at work to make ends meet at the end of the month, as Ms Antonia, headteacher in Maputo, explains:

I teach at night courses at a different institution. You cannot assume that when I get there at 5pm I am as fresh and rested as I am when I get here at 7 am. Sometimes I am just exhausted. My students understand it, because they are probably exhausted too if they come from a hard day's work. This is what I mean by mutual understanding. We do not require as much of them, and they do not require as much of us. To be completely honest, sometimes I just do not bother going. When you know you are going to give a 10\% of what you could, and they are going to grasp a $10 \%$ of that $10 \%$... you start asking yourself some questions.

Going to school at night entails therefore a number of difficulties that directly impinge on the quality of teaching and learning.

A fourth factor leading girls to leave school has to do with not having anyone to leave the baby with in that specific time slot, as happened to Ersilia:

I think it will be even more difficult to go to school at night when the baby is here. Who would I leave the baby with? My mum works at the market and she comes back home at 7.30pm. I cannot rely on her for looking after the baby because I have to be at school at 5.45pm. It would be much easier during the day because I would easily find somebody ... a relative, or a neighbour for instance.

Childrearing responsibilities are usually shared within the extended network. As the concept of a nuclear family makes little sense in Mozambique, no couple would be expected to raise their children independently from their extended family. However the time slot night courses require presents some difficulties: it is too early to leave the baby with those who work during the day and too late to leave them with those that have not worked and who have to look after their own family members. Extended family members are also navigating work and life patterns in different ways. This suggests that although discourses of both motherhood and the family are produced globally, they are invoked locally. This produces conflicts, which tend to remain invisible to the global arena.

Last, a fifth factor concerns the nature of night courses, which were ideally developed in order to give adults who did not attend as children the opportunity to develop literacy skills. This means that night courses do not tailor to the educational needs of young people. Moreover, as adults are likely to attend night courses, there may be a substantial age gap between classmates, making it more difficult to integrate and create a feeling of community in the classroom.

For these reasons, the boundaries between transfer and expulsion are blurred, and the risk of dropout implied in a transfer cannot be overlooked. For instance 7 of the 25 girls interviewed for this study were not in education at the time of the interview. All of them preferred dropout over night attendance. Of the remaining 18 girls, 8 had managed to remain in their day courses through different stratagems, while 10 were currently attending night courses under duress.

So, if night attendance is so problematic, why is it that national policy encourages pregnant girls to transfer? I contend that this may be due to the contrast between discourses associated 
with pregnancy and education, which position the two in opposition to one another. The result is a deficit view of the pregnant schoolgirl. In the next section I will look closely at the policy text in order to tease out the main discourses that contribute to producing it.

\section{De-constructing Policy / Constructing Pregnancy}

In this section I trace how in-school pregnancy is constructed and highlight the discursive imperative for its management. I do this by analysing specific excerpts of the policy text which construct in-school pregnancy as invisible by conflating 'unwanted' with 'unplanned' (Section 5.1), as criminal by treating it as an offence which requires punishment (Section 5.2) and as medicalised, by using words such as contagion and prevention (Section 5.3).

\section{$\underline{5.1 \text { Invisible Pregnancies }}$}

The high rate of school dropout is due to schoolgirls presenting themselves pregnant during the school year. (Decree 39/GM/2003)

This excerpt from the policy text refers to the concept of drop-out in connection with in-school pregnancy. It states a cause and effect relationship between pregnancy and dropout that implies a dichotomy between pregnancy and schooling. Moreover, pregnancy is constructed as an event that happens to girls, or which they encounter passively. The wording 'schoolgirls presenting themselves pregnant' is not commonly used in English, but it conveys a passivity around girls with respect to their pregnancy. In other words, pregnant schoolgirls are disconnected from their agency in a fashion that resonates with Western conceptualisation of teenage pregnancy as unwanted and unplanned.

By constructing pregnant schoolgirls as passive, the policy (re)produces the binary between passive/active alongside a deficit view of the pregnant schoolgirl. This notion of schooling is tightly interwoven with institutional regimes structured around an intersection of gender and age which assumes the child. In other words, the exclusion of pregnancy from the childhood/education couplet normalises a linear and uniform identity throughout the text of the policy. Pregnancy is thus constructed as an event that creates hindrances to the 'normal' development of the individual. Pregnancy as a marker of adulthood works against the notion of schoolgirl and the necessary infantilisation of pupils within school structures and practices. This restrictive institutional context, which has also been reported in Ghana by Dunne \& Ananga (2013), presupposes individual identities as linear and coherent and does not encourage inclusion of students who deal with multiple identities and belongings, as Alzira:

When I go to school, I take Ines to my parents-in-law, and they look after her while I am at school.

Alzira wore many hats during her day. She lived at home with her parents, but was in a relationship with the father of her daughter. She looked after her child together with her family, but also relied upon her in-laws by bringing her daughter to their home every day before going to school. The multiplicity of her identities put Alzira at odds with the institutional regime of the school and forced her to enact strategies to oppose being normalised into night courses.

Given the exclusion of the possibility of pregnancy from the normalised identity constructed within institutional regimes, in-school pregnancies are constructed as unwanted and unplanned. 
See for instance Lidia, a sixteen year old mother who dropped out of school in connection with her pregnancy.

\section{Francesca: Let's talk about your first pregnancy.}

\section{Lidia: Ah what can I say? It happened.}

Lidia's boyfriend did not recognise their son and recently moved to another town. She left school and was looking after her child full-time, while contributing to her household, when I met her. The specific wording chosen by Lidia seemed to indicate the need to put some distance between herself and her pregnancy, to the point that I got the impression she was disconnected from her pregnancy. Responses such as these have been the norm during fieldwork, as respondents seemed to connect their pregnancies to God's will or preferred to leave them unaccounted for, as Lidia did. On one level, this resonates with the policy text in that it reproduces a discourse of unwanted-ness and lack of planning. At the same time, the disembodiment transpiring from Lydia's words becomes an active tool through which she protects the narrative of her identity in a time of difficulties. In this sense, representing a pregnancy as unwanted becomes an act of resistance and therefore of agency.

In this sense, Lidia performs an act of resignification (Butler 1990) by means of signalling awareness to existing discourses while also navigating and reshaping them in order to tell new stories about pregnancy and herself. As Taylor $(2011,827)$ puts it:

'will' or 'intent' of the subject is always caught up in the discourse which produces it and exceeds it, and while 'will' or 'intent' must be understood as an agentic effect in discourse and not an essentialised attribute of a person, nevertheless the scope for acting purposefully remains.

Positioning individuals within discourses does not mean robbing them of their agency, but requires an understanding of their nature from a point that is external to them. Teenage pregnancies can be as planned as later pregnancies. Cater and Coleman (2006) for instance suggest that teenage pregnancies are instrumental in accomplishing positive changes in the mother's life. Pregnancies become a means to develop a new identity, feel useful to others and enhance one's self-esteem. Pregnancies can be wanted and planned, as Zara suggested:

Maybe a girl wants to get pregnant, have babies, raise her own family. Maybe her own parents do not have anything against this and support her. So what is bad about this?

Allowing conceptual space for this would render the policy more relevant to girls' experiences. It would also entail a reconceptualisation of institutional regimes directed towards a more open understanding of how to achieve inclusion.

Another aspect of this discussion has to do with a discourse of age-appropriateness, which suggests there may be more regulatory framework at play. For instance, as school entry is often delayed and grade repetition is frequent, girls may be married or engaged by the time they attend secondary school. This marital status goes hand in hand with a whole set of social expectations, pregnancy being one of the main ones, as Ms Emilia, a Ministry of Education (MINED) official, points out:

Girls are already loboladas [married off] in their own communities. As a consequence they are considered adults and getting pregnant is normal if that is 
the case. So both their communities and their families encourage them to get pregnant.

Emilia suggests a clash may exist between schools and families in relation to pregnancy. Albeit figuring as marker of adulthood within both contexts, pregnancies may be encouraged within communities, while existing discourses within schools are directed to delaying them. In this sense, Decree 39/GM/2003 offers no possibility for dealing with the idea of either wanted or planned pregnancies, rendering them invisible and thus causing a gap which affects both policy reception and implementations.

Research participants generally struggled to grasp this lack of understanding and felt the policy left them voiceless. In-school pregnancies create a space for the regulation of subjects, which works concurrently along the moral/legal dimension of crime and punishment, and the medicalised discourse of contagion/prevention, which will be discussed in the next section.

\subsection{Criminalising Pregnancies}

[...] there is the need to adopt means of prevention and reprehension of such events, as specified by the following actions, to be taken with immediate effect. (Decree 39/GM/2003)

A key point of this excerpt is the need to regulate. The modalities through which this need is accomplished can be illuminated through Foucault's concept of power, which works to both punish culprits and as a deterrent for future crimes (1977). As Foucault (ibid.) reminds us, there is an aspect of visibility of the punishment, which is directed to deter other similar crimes from happening in the future. As such, prevention is implicit in punishment, it indicates that the two concepts are merged within the policy extract, despite being conceptually different. Prevention invokes the field of medicine and is employed here as a means to avoid contagion.

The word 'reprehension', meaning a moral condemnation of an event, implies both distaste and the need to address or prevent the event from occurring. In this case, in-school pregnancy is the distasteful event that is the focus of censure which in common sense interpretation is difficult to separate from associated punishment. The issue of punishment is problematic because if there is a fine, there should be an offence. This raises more questions. What is the crime? Is pregnancy a crime? If pregnancy is the crime, who is the perpetrator and who is the victim? These are the questions raised by Arthur \& Cabral (2004) with respect to the measure of transferring pregnant school girls to night courses.

Within schools, age-appropriateness of pregnancy plays a part in defining the crime. As pregnancy and (hetero) sexual practices signify adulthood, their incidence during earlier phases of life and during schooling confronts normative understandings of childhood and adulthood. In-school pregnancy, in this sense, blurs accepted boundaries, and definitions of childhood and adulthood.

The Decree recognises that in-school pregnancies

\section{[...] are often the outcome of the illicit development of an unprofessional relationship between male teachers and schoolgirls. (Decree 39/GM/2003)}

By identifying the relationship behind pregnancies, the policy implies a power differential, whereby male teachers are more powerful by means of both their gender and seniority. Yet, 
men are rarely penalised, and the indications contained in Decree 39/GM/2003 in this respect do not make it beyond the official act. This is mainly due to two reasons. First, men or boys involved with girls' pregnancies rarely attend the same school as the girls, although they are often members of the local community. Secondly, the men responsible for the pregnancy may work in the school as teachers, where they tend to occupy positions of greater social power than the pregnant girl. Teachers' involvement with schoolgirls is perceived to be very high in Mozambique, although no quantification is provided by current literature. However, teachers continue to work unaffected by the decree's disposition, even if they have been publicly recognised as 'guilty' (Arthur and Cabral 2004). This is possibly because the supply of teachers in Mozambique is limited and demand for schooling is high.

Schoolgirls, on the other end, are already in deficit, laying the grounds of their production as 'victims' and without agency. At the same time, girls carry the visible sign of the crime - the pregnancy itself - and are the ones who receive the main punishment. In this sense it seems contradictory to punish the victim. Some adult interviewees were aware of the contradictions of transferring pregnant girls to night courses, recognising that life would become more difficult for girls who are already dealing with a pregnancy. Yet, the need to punish - and to punish girls themselves - remained quite a strong drive for them, Mr Paulo (MINED) asserts:

We need to strengthen the mechanisms for punishment. If there is no punishment for girls, they will keep getting pregnant in schools.

With his words, Mr Paulo invokes a second aspect of the need to punish, which acts as a means to deter other girls from getting pregnant. Ms Antonia, headteacher, furthers:

We do not want to have more girls getting pregnant in the same class because we were not strict enough to move one to night courses. So to some extent, we transfer one, but by so doing, we protect the interests of a number of others.

If pregnancy renders visible the crime of engaging in non-appropriate behaviours for one's age, and of challenging the institutional regime, the visibility of punishment needs to rebalance the situation and act as a deterrent. Punishment becomes then a way to protect institutional regimes and ensure adherence to its norms.

Punishment cannot lead to redemption for the offender, as a pregnancy that gets to the point of triggering punishment is probably a pregnancy that cannot be undone ${ }^{1}$. It means therefore that there is no going back to being childless, which renders the idea of a punishment entirely useless from the perspective of a tentative rehabilitation. Punishment becomes instead a form of gender and bodily regulation directed to the control of the female body. It is for this reason that it becomes important to address not only which crime is being punished, and whose, but also for whose benefit a punishment is being put into place.

The discourse of punishment points directly towards the opposition education/pregnancy. For instance Ms Antonia in her interviews talks of her own experience of being a student:

I did not have any kids myself, and I am glad, because I had the time and the space to invest in my education, and to get where I am now. It is a struggle, it is always a struggle.

\footnotetext{
${ }^{1}$ Pregnancies may also be interrupted and would not, in this case, lead to a transfer.
} 
In her interview, Ms Antonia discussed how hard it had been to get to where she was, how she had no time for socialising when she was in education and how she felt she had no options to have children. In her experience, women are not allowed to have both; they can either invest in family life or in their career. For her, having a child while you are still in education is a clear indication that you will not invest in your career, and so why should schools keep your place and not give it to somebody that may be more interested in investing in her (modern) aspirations?

This suggests that education and equality are viewed as a privilege, which pregnancy undermines and threatens. Similarly, Decree 39/GM/2003 is an instrument for the reproduction of a modern social order, in which training and education are important means for personal development. However, those allowed to reap the benefits of the education system in these developmental terms must comply with a set of rules that includes the postponement of pregnancy.

The analysis in this section has indicated how Decree 39/GM/2003 draws on several discourses that position the education/pregnancy nexus as oppositional, problematic and in need of regulation. In the next section, I will address the relevance of a medicalised discourse.

\section{$\underline{5.3 \text { Medicalised Pregnancies }}$}

Discourses of crime and punishment in Decree 39/GM/2003 discussed in the previous section also bring with them notions of contagion and emulation in depicting in-school pregnancy. By reinforcing each other, these discourses construct in-school pregnancy as a looming event that disrupts girls' educational careers and transitions into adulthood. Mr Cassimo, History teacher, suggests:

\section{By implementing that measure, we aim at weakening the occurrence of pregnancy in school. See, if they were to get pregnant and receive no punishment, the other girls in the class would want to do the same too, to get pregnant I mean.}

Pregnancy is seen as a disease that easily spreads within the classroom and needs to be contained. Transferring pregnant girls to night courses becomes a way to protect other girls from the threat of an impending contagion. It is similar to medical isolation required in highly infectious diseases. Such an interpretation of in-school pregnancy finds its reiteration in the phrasing of the Decree itself and in the words of many of my adult research participants. For instance Ms Alberta, a technical advisor to a sexual health international NGO, states:

There is the widespread idea that in-school pregnancy is like a disease: if you have a pregnant girl in the classroom, other girls will get pregnant too.

The relevance of this interpretation of pregnancy can be grasped in connection with two different discourses. The first considers in-school pregnancy as an infection, borrowing terminology from the medicalisation of pregnancy. The second shifts the focus from a condition to the pregnant girl, invoking psycho-developmental discourses of adolescence. Both perspectives tend to essentialise in-school pregnancy, viewing it as physiologically hazardous because of either physical immaturity or psychological weaknesses. These explanations work to frame teenage pregnancies as generally undesirable and objectify in-school pregnancy as a pathology requiring treatment. 
This medicalisation of the field of sex and sexuality echoes that which surrounds the HIV/AIDS pandemic. Talks of symptoms, risks, and prevention abound as a consequence. The following quote, from Dr Anais, MINED official, is quite insightful in that regard:

Also, you should not forget that pregnancy has some symptoms, and these should not be shared with others, as they would make the rest of the class waste a lot of time. Consider if she needs to go to the toilet a lot, if she feels sick, and the rest of the class naturally want to assist her. This translates into a lot of time wasted for the normal school day. And in psychological turmoil for everybody.

Dr Anais claimed that pregnancy had symptoms which may impinge on the process of learning. These should be kept out of the classroom in order to allow those who do not present them to carry on with their activity. Pregnancy, in Dr Anais' words, is no different to any other disease. The bottom line is that if you are ill you stay at home and do not attend school. Mr Sampson, teacher in Maputo, raised the same concern:

It is difficult to deal with pregnant girls in the classroom. These are problematic pregnancies, because their bodies are too young, and they suffer more. So it happens that girls faint in the classroom, they feel sick and need to leave the room... it ends up in prolonged absenteeism for them, and it is disruptive for the other kids.

The medicalisation of pregnancy translates into practical classroom problems, depicting pregnancy as a disability that challenges the role of the teacher in the class. Another aspect of the medicalisation of pregnancy can be drawn from the unpreparedness of the body to carry a pregnancy to term. This is often seen to result in increased medical conditions rendering pregnancies difficult and dangerous. Although international reports are rife with descriptions of medical complications connected with the young age of the mothers (WHO 2004, 2006), it remains unclear whether the risks associated with teenage pregnancy are biologically related to the age of the mother, or to social factors connected to the pregnancy.

The discourse of medicalisation is also appreciated by Father Jorge, headteacher of the Catholic School:

I am aware that the Ministry of Education endorses this measure of transferring pregnant girls to night classes, but I do not agree. It seems to me that they are afraid a pregnant girl will make the others turn pregnant too, as if it were a disease. Now, pregnancy is not contagious!

Of course pregnancy is not contagious in a biomedical sense, but using a medical terminology serves well the purpose of explaining its sustained rates, suggested Mr Mario, teacher:

Last, but not least, I think Decree 39/GM/2003 expresses the need to contain the phenomenon of in-school pregnancies. By removing pregnant girls from their classes, by punishing the culprits, so to speak, you prevent pregnancies from spreading out. Because, believe me, if you do nothing, they will.

However, if in-school pregnancy is not contagious in a biomedical sense, how does it spread out? Mr Fernando, teacher in Maputo, suggests:

[Transferring pregnant girls to night courses] is also a way to inhibit imitation. They are adolescents you know, if one gets pregnant the others may think 'well, if she is pregnant, why can't I? 
In-school pregnancy is thus framed in psychoanalytical terms as a behaviour that young people will want to imitate, invoking discourses of adolescence. Mr Cassimo added:

If one gets pregnant, others will want to experiment too. Behavioural attitudes play a huge role in this phase, teenage I mean. The pregnant girl is the one who did something new, something innovative. Hence the emulative attitude of the others, who are going through that phase in which they want to experiment everything.

Older people tended to see teenagers as weak-willed and prone to peer pressure. However, they were not the only ones, as some young people shared the same view, such as Gloria, taking part in a mixed gender focus group in Maputo:

Pregnant girls do not influence others by telling them to get pregnant. Just the fact that they are there, that they do the same things that they did before getting pregnant, the fact that there seem to be no consequences... that is an influence in itself. And non-pregnant girls are easy to be influenced this way.

In other words, the visibility of pregnancy becomes contagious when not counterbalanced by the visibility of punishment. This reinforces the need to regulate, hence the transfer as indicated by Decree 39/GM/2003. This need is discursively constructed, and contributes to producing a deficit view of pregnant schoolgirls. This view invokes the dichotomy childhood/adulthood as inherent to the institutional regime reproduced by schools, which infantilises pupils regardless of their backgrounds and multiple belongings. Legal/moral discourses of crimes, medicalised understandings of prevention and contagion and the psycho-developmental concept of adolescence all concur in establishing a difference between pregnant and non-pregnant girls. Because of the emphasis cast upon this difference, this begs the question: is the concept of dropout enough to capture the experiences of pregnant schoolgirls?

\section{Dropout or Throw-Out?}

In this concluding section I draw on the arguments developed so far to expand the notion of dropout by integrating that of throw-out. I have claimed in Section 4.2 that factors connected with night courses may render attendance problematic. These factors, combined with the production of a non-agentic, deficit subject of the policy and institutional regulatory discourses suggest push factors may play a substantial part in dropouts, calling for an integration in the notion of throw-out.

Dunne \& Ananga (2013), in their paper on dropout in Ghana, indicate that institutional definitions tend to offer static conceptualisations of dropout, which simply refers to someone who leaves the education system without achieving a degree or terminal qualification (UNESCO-UIS 2005, OECD 2002). School abandonment - Dunne \& Ananga (ibid.) claim further -is a process that happens over time, and which entails different factors. This paper contributes to the nuancing of dropout processes by highlighting how institutions indirectly encourage dropout by requiring the normalisation of pupils' identities in order to adhere to institutional regimes. Zara, a young mother who participated in a girls-only focus group in Maputo, suggested:

A healthy environment would not cast any shame on a pregnant girl. A pregnant girl would not have that urge to leave and hide from her peers. I think that a pregnancy cannot be negative or wrong. What is negative is the discrimination within the school. It is not the pregnancy that discriminates, it is the school. 
This last quote very succinctly elaborates how the policy regulation of in-school pregnancy produces local conditions in which processes of exclusion and discrimination operate through institutional life in schools. The hidden operation of these regulatory techniques in turn focuses on the pregnancy rather than on the very school processes and social relations that produce the social and educational exclusion. In other words, policy indications effectively push pregnant girls out of the school system. I have illustrated how discursive strains produce the pregnant school girl as transgressing certain boundaries, for instance those pertaining to the childhood/adulthood opposition. Educational institutions, on the other hand, work to normalise these behaviours, and do so by developing sets of norms aimed at reproducing an institutional regime and at positioning individual identities accordingly.

Most critically, these discursive framings and processes of regulation work to produce the pregnant school girl as lacking agency both in the process of becoming pregnant and in her educational future. At the same time, they indicate that girls should be held responsible and thus bear the brunt of the punishment, to be administered via transfer to night courses. Last, by invoking a medicalised discourse of prevention and contagion, the policy further essentialises the categories of childhood and adulthood, objectifying in-school pregnancy as deviance, and pregnant schoolgirls as failed individuals.

In conclusion of these considerations, I find that Luker's notion of 'throw-out' $(1996,9)$ illuminates the mechanisms through which education institutions fail to operationalise inclusion. Pregnant schoolgirls do not leave school as a direct result of the pregnancy. Instead, school abandonment seems to happen in association with 'the structures that banned pregnant teachers and students from school grounds' (ibid.). Acknowledging push factors should not overshadow pull factors (childrearing responsibilities, household duties, and the like), but should instead contribute to a nuanced understanding of the obstacles pregnant girls encounter while they are in formal education.

\section{Conclusion}

With this paper I have made visible the complexities within the pregnancy/education nexus at a policy and institutional level. In order to do so, I have considered the construction of inschool pregnancy through the current policy text in Mozambique. According to Decree $39 / \mathrm{GM} / 2003$, in-school pregnancy hinders school completion. It is contagious both in a biomedical and behavioural sense, in that its presence in the classroom might proliferate if nothing is done. In-school pregnancy is ultimately seen to require some form of punishment, which is imparted through transfer to night courses.

Respondents' perspectives suggest that such measures may be regarded as beneficial on more than one level. At the outset, transfer condemns pregnancy and acts as a deterrent for future potential pregnancies; it protects pregnant girls from discriminatory acts supposedly carried out by classmates and it prevents contagion by separating pregnant from non-pregnant girls. Furthermore, it seems to be in line with international agreements in that it contributes to fighting one of the main obstacles to girls' education - namely, pregnancy - as well as representing a move to greater inclusion. Pregnant schoolgirls do have access to some form of education when previously they would have simply suffered expulsion from school.

Data and analysis generated through this study suggest however that transfer to night courses may not be as beneficial as envisaged, acting as a highway towards school abandonment. Going 
to school at night is more difficult for a number of reasons, namely the scarcity of transport, increased risks connected with being out and about at night, difficulties in finding childcare at night and the reduced quality of night courses, which make the effort of going questionable, to say the least. Decree 39/GM/2003 contribute to reproducing an institutional regime built around the infantilisation of its subjects, and works accordingly towards their normalisation.

In this respect, I support the nuances offered by the notion of 'throw-out' (Luker 1996), which creates a space for identifying push factors connected with a school dropout, such as Decree 39/GM/2003 which contradictorily closes down access for pregnant girls and young mothers. Although the Decree apparently improved the predicament of pregnant schoolgirls and young mothers prior to its implementation in 2003, its consequences are likely to bring about little change. Regardless of whether it plays out as dropout or throw-out, pregnancy-related school abandonment transfers the cost of a pregnancy beyond the school grounds, to the young women themselves and often to families and communities. Transferring a cost can by no means be considered a solution to the 'problem' of in-school pregnancy. I have suggested here that appealing the construction of in-school pregnancy as a problem may offer a more insightful and nuanced perspective over the lives of young women in education. 


\section{References}

Amadiume, I. 1997. Reinventing Africa. Matriarchy, Religion and Culture. London: Zen Books.

Andrade, Ximena, Ana Maria Loforte, Conceiçao Osorio, Lucia Ribeiro, and Eulalia Temba. 2001. Famìlias em Contexto de Mudanças em Moçambique. In A Mulher e a Lei na Africa Austral. Investigaçao e Educaçao. Maputo: Women and Law in Southern Africa (WLSA).

Arnfred, Signe. 2004. Conception of Gender in Colonial and Post-Colonial Discourse: The Case of Mozambique. In Gender Activism and Studies in Africa: CODESRIA.

Arthur, Maria José, and Zaida Cabral. 2004. "Essas Gravidezes que Embaraçam As Escolas. Violação dos Direitos Humanos das Jovens Adolescentes." Outras Vozes 7.

Bakare-Yusuf, Bibi. 2004. "Yoruba's Don't Do gender": A Critical Review of Oyeronke Oyewumi's The Invention of Women: Making an African Sense of Western Gender Discourses Dakar: CODESRIA.

Bhana, D., L. Clowes, R. Morrell, and T. Shefer. 2008. "Pregnant girls and young parents in South African schools." Agenda 22 (76):78-90.

Bhana, Deevia, Robert Morrell, Tamara Shefer, and Sisa Ngabaza. 2010. "South African teachers' responses to teenage pregnancy and teenage mothers in schools." Culture, Health \& Sexuality 12 (8):871-883. doi: 10.1080/13691058.2010.500398.

Blaikie, Norman. 2007. Approaches to Social Enquiry. 2nd ed. Cambridge (UK): Polity Press.

Butler, Judith. 1990. Gender trouble : feminism and the subversion of identity. New York, N.Y. ; London: Routledge.

Chankseliani, Maia. 2008. "Gender inequality in Mozambican primary education: problems, barriers and recommendations." Political Perspectives 2 (1):1-30.

Chilisa, Bagele. 2002. "National Policies on Pregnancy in Education Systems in Sub-Saharan Africa: the case of Botswana." Gender and Education 14 (1):21-35.

Coleman, Lester, and Suzanne Cater. 2006. ""Planned" Teenage Pregnancy: Perspectives of Young Women from Disadvantaged Backgrounds in England." Journal of Youth Studies 9 (5):593-614.

Dunne, M. 2007. "Gender, Sexuality and Schooling: Everyday Life in Junior Secondary Schools in Botswana and Ghana." International Journal of Educational Development 27:499-511.

Dunne, Máiréad, and Eric Daniel Ananga. 2013. "Dropping Out: Identiy Conflict in and out of School in Ghana." International Journal of Educational Development 33 (2):196-205.

Eloundou-Enyegue, Parfait M., J. Mayone Stycos, and Fatou Jah. 2004. "Integrating Education and Population Policy: The Gender-Equity Payoffs of Reducing Pregnancy-Related Dropouts." Annual Meeting of the Population Association of America, Boston.

Foucault, Michel. 1977. Discipline and Punish: The birth of the prison. London: Penguin Books.

Foucault, Michel. 1994. Power: Essential Works of Foucault. Vol. 1. London: Penguin Books.

Foucault, Michel, and Colin Gordon. 1980. Power/knowledge : selected interviews and other writings, 1972-1977. Brighton: Harvester P.

Grant, M., and K. Hallman. 2006. Pregnancy-related school dropout and prior school performance in South Africa. In Policy Research Division Working Paper n. 212. New York: Population Council.

Hall, Stuart. 1996. "Introduction: Who Needs Identity?" In Questions of Cultural Identity, edited by Stuart Hall and Paul Du Gay, 1-17. London: Sage.

Iliffe, J. 2005. Honour in African History. Cambridge: Cambridge University Press. 
Jewkes, Rachel, Robert Morrell, and Nicola Christofides. 2009. "Empowering teenagers to prevent pregnancy: lessons from South Africa." Culture, Health \& Sexuality 11 (7):675-688.

Jewkes, Rachel, Caesar Vundule, Fidelia Maforah, and Esme Jordaand. 2001. "Relationship dynamics and teenage pregnancy in South Africa." Social Science and Medicine 52:733-744.

Kessler, S., D. J. Ashenden, R. Connell, and G. W. Dowsett. 1985. "Gender Relations in Secondary Schooling " Sociology of Education 58:34-48.

Laws, Cath. 2011. Poststructuralism at Work with Marginalised Children. Edited by Bronwyn Davies, Rethinking Research and Professional Practice in terms of Relationality, Subjectivity and Power: Bentham Science Publishers.

Loforte, A.M. 2007. "Inequidades e Valores em Saúde Reprodutiva: Vulnerabilidade das Mulheres num Contexto de Feminização da SIDA " In Mulher, SIDA e o Acesso a Saúde na Africa Subsahariana, sob a perspectiva das Ciências Sociais edited by M.C. Alvarez Degregori, E. Leandro Reguillo and S. DiGiacomo, 27-35. Barcelona: Medicaus Mundi Catalunya.

Luker, Kristin. 1996. Dubious Conceptions. The Politics of Teenage Pregnancy. Cambridge (USA) and London (England): Harvard University Press.

Macleod, Catriona. 2011. "Adolescence", Pregnancy and Abortion. Constructing a Threat of Degeneration. Edited by Jane Ussher, Women and Psychology. London and New York: Routledge.

Meekers, Dominique, and Ghyasuddin Ahmed. 1999. "Pregnancy-related school dropouts in Botswana." Population Studies 53:195-209.

Mikell, G. 1997. "Introduction." In African Feminism: The Politics of Survival in Sub-Saharan Africa, edited by G Mikell, 1-50. Philadelphia: University of Pennsylvania Press.

Mkhwanazi, Nolwazi. 2010. "Understanding teenage pregnancy in a post-apartheid South African township." Culture, Health \& Sexuality 12 (4):347-358. doi: 10.1080/13691050903491779.

Morrell, Robert, Deevia Bhana, and Tammy Shefer, eds. 2012. Books and Babies: Pregnancy and Young Parents in Schools HSRC Press.

Nguenha, Alcido Eduardo. 2003. Despacho 39/GM/2003. edited by Ministerio de Educaçao. Maputo (Mozambique).

OECD. 2002. Education at a Glance. Paris.

Osório, Conceição, and Teresa Cruz e Silva. 2008. Buscando sentidos. Género e sexualidade entre jovens estudantes do ensino secundário, Moçambique. Maputo: CIEDIMA, SARL.

Preston-Whyte, Eleanor, and M. Zondi. 1992. "African Teenage Pregnancy: whose Problem?" In Questionable Issue: Illegitimacy in South Africa, edited by S. Burman and Eleanor Preston- Whyte. Cape Town: Oxford University Press.

Price, Neil, and Tristan Hawkins. 2001. "Young People's Sexual and Reproductive Health: Towards a Framework for Action." In Managing Reproductive Life. Cross-Cultural Themes in Fertility and Sexuality, edited by Soraya Tremayne. New York and Oxford: Berghahn Books.

Runganga, A.O., J Sundby, and P Aggleton. 2001. "Culture, Identity and Reproductive Failure in Zimbabwe " Sexualities 4 (3):315-332.

Shefer, T., D. Bhana, and R. Morrell. 2013. "Teenage pregnancy and parenting at school in contemporary South African contexts: deconstructing school narratives and understanding policy implementation." Perspectives in Education 31 (1):1-10. 
Taylor, Carol A. 2011. "'Hope in failure': A Level students, discursive agency, post-feminism and feminism." Gender and Education 23 (7):825-841. doi: 10.1080/09540253.2010.538013.

Thomas, L. 2007. "Gendered Reproduction: Placing Schoolgirl Pregnancies in African History." In Africa After Gender?, edited by C Cole, T Manuh and S Miescher. Bloomington: Indiana University Press.

UNESCO-UIS. 2005. Children Out of School: Measuring Exclusion from Primary Education Montreal.

UNFPA. 2013. Motherhood in Childhood. Facing the Challenge of Adolescent Pregnancy. In The State of the World Population.

WHO. 2004. Adolescent Pregnancy. Issues in Adolescent Health and Development. Geneva.

WHO. 2006. Pregnant Adolescents. Delivering on Global Promises of Hope. Geneva: WHO,.

Youdell, Deborah. 2006. Impossible bodies, impossible selves : exclusions and student subjectivities. Dordrecht: Springer. 